\title{
Cerebral autosomal dominant arteriopathy with subcortical infarcts and leucoencephalopathy vs. multiple sclerosis. Either one or sometimes both?
}

\author{
George P. Paraskevas, Vasilios C. Constantinides, Elisabeth Kapaki \\ Cognitive and Movement Disorders Clinic and Neurochemistry Unit, 1st Department of Neurology, National and Kapodistrian University of \\ Athens, School of Medicine, Eginition Hospital, Athens 11528, Greece.
}

Correspondence to: George P. Paraskevas, Cognitive and Movement Disorders Clinic and Neurochemistry Unit, 1st Department of Neurology, National and Kapodistrian University of Athens, School of Medicine, Eginition Hospital, 72 Vas. Sophias Ave, Athens 11528, Greece. E-mail: geoprskvs44@gmail.com

\begin{abstract}
How to cite this article: Paraskevas GP, Constantinides VC, Kapaki E. Cerebral autosomal dominant arteriopathy with subcortical infarcts and leucoencephalopathy vs. multiple sclerosis. Either one or sometimes both? Neuroimmuno/ Neuroinflammation 2018;5:49. http://dx.doi.org/10.20517/2347-8659.2018.50
\end{abstract}

Received: 27 Aug 2018 First Decision: 17 Oct 2018 Revised: 5 Nov 2018 Accepted: 14 Nov 2018 Published: 14 Dec 2018

Science Editor: Athanassios P. Kyritsis Copy Editor: Cui Yu Production Editor: Huan-Liang Wu

\begin{abstract}
Cerebral autosomal dominant arteriopathy with subcortical infarcts and leucoencephalopathy (CADASIL), is the most common cause of inherited cerebral small vessel disease, inherited stroke and inherited vascular dementia. It is not infrequent for CADASIL to be mistaken and mistreated for multiple sclerosis (MS). A much less frequent but existing scenario is the co-occurrence of CADASIL and MS (or MS-like inflammatory condition). Such patients may present with spinal cord lesions, brain or spinal cord enhancing lesions, positive oligoclonal bands and high IgG index in the cerebrospinal fluid and good response to corticosteroids or immunomodulating treatments. CADASIL through various mechanisms may trigger or modulate autoimmune reactions, and either be complicated by an inflammatory component or cause an MS-like disorder.
\end{abstract}

Keywords: Cerebral autosomal dominant arteriopathy with subcortical infarcts and leucoencephalopathy, multiple sclerosis, autoimmunity, NOTCH3

\section{INTRODUCTION}

Cerebral autosomal dominant arteriopathy with subcortical infarcts and leucoencephalopathy (CADASIL), caused by mutations in $\mathrm{NOTCH}_{3}$ gene ${ }^{[1]}$ is the most common cause of inherited cerebral small vessel disease, inherited stroke and inherited vascular dementia ${ }^{[2]}$. Patients typically present with various combinations of

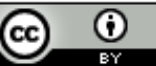

(C) The Author(s) 2018. Open Access This article is licensed under a Creative Commons Attribution 4.0 International License (https://creativecommons.org/licenses/by/4.0/), which permits unrestricted use sharing, adaptation, distribution and reproduction in any medium or format, for any purpose, even commercially, as long as you give appropriate credit to the original author(s) and the source, provide a link to the Creative Commons license, and indicate if changes were made.

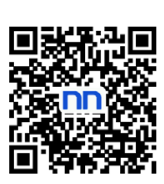



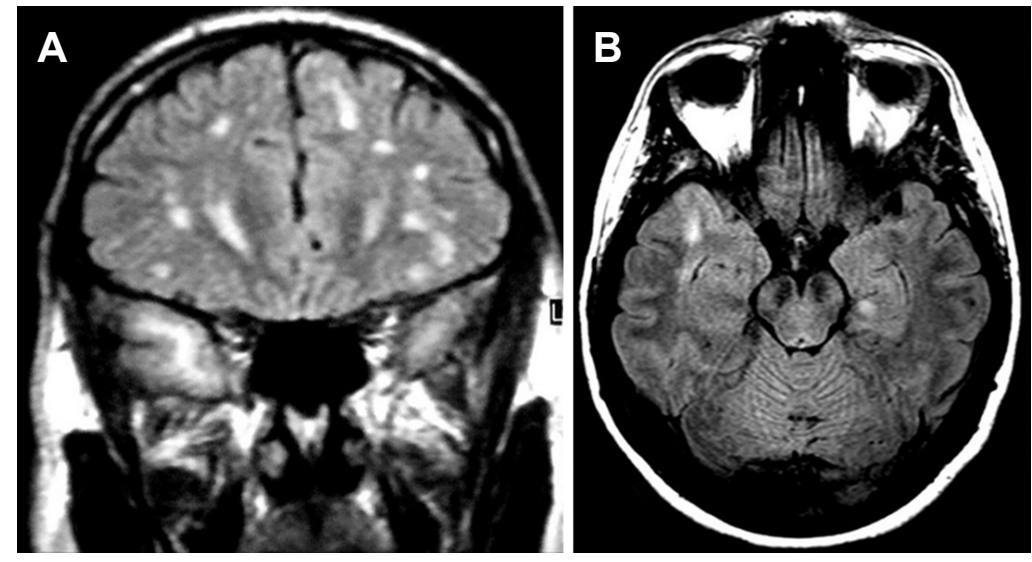

Figure 1. Magnetic resonance imaging of two patients (Fluid Attenuated Inversion Recovery images). (A) A 38-year-old male with CADASIL and multiple hyperintense lesions. Due to his age, they were initially thought by the radiologist to represent MS. However, anterior temporal lobe lesions prompted genetic testing, revealing the correct diagnosis; (B) The opposite may also occur. This 31-yearold female with the right anterior temporal lesion suffers from relapsing-remitting MS with oligoclonal bands and high IgG index in the CSF. Genetic testing of NOTCH3 was negative. CADASIL: cerebral autosomal dominant arteriopathy with subcortical infarcts and leucoencephalopathy; MS: multiple sclerosis; CSF: cerebrospinal fluid

migraine with aura, stroke or transient ischemic attacks (TIAs), in the presence of multiple and progressively confluent white matter ischemic lesions involving, among others, the anterior temporal lobe and the external capsule $^{[3]}$. As the load of ischemic lesions increases and the disease progresses, behavioral and psychiatric symptoms, vascular dementia and motor disability become evident ${ }^{[4]}$. Atypical presentations may exist and the clinical differential diagnosis may be extensive ${ }^{[5]}$. Diagnosis is confirmed by genetic testing of the $\mathrm{NOTCH} 3$ gene $^{[1,4]}$.

\section{CADASIL MISDIAGNOSED AS MULTIPLE SCLEROSIS}

It is long known that, during the early or middle stages of CADASIL, recurrent ischemic events and multiple white matter lesions may mimic multiple sclerosis (MS $)^{[6]}$ [Figure 1]. Autosomal dominant inheritance, migraine with aura, characteristic involvement of the anterior temporal lobe, ischemic lesions within the basal ganglia and deep nuclei such as the thalamus and, later on, dementia may point towards CADASIL. On the contrary, lesions present exclusively in the white matter (especially the periventricular white matter) and the corpus callosum, spinal cord involvement, history of optic or retro bulbar neuritis and the additional presence of oligoclonal bands in the cerebrospinal fluid, may point towards MS [Table 1]. However, some of the above may be absent, unrecognized, atypical or not reported. Patients with de novo NOTCH3 mutations and, thus, with negative family history have been described ${ }^{[7]}$, while familial forms of MS are known to exist and enter in the differential diagnosis ${ }^{[5]}$. Migraine with aura or the characteristic anterior temporal lesions may be absent in almost $50 \%$ and $25 \%$ of CADASIL patients respectively ${ }^{[8]}$ and these percentages may be even larger in patients of Chinese origin ${ }^{[9]}$. Corpus callosum or pericalosal lesions (typically present in MS) may also occur in CADASIL ${ }^{[3,10-12]}$. Atypical features may increase diagnostic confusion and increased clinical suspicion may be needed to prompt diagnostic testing of $\mathrm{NOTCH}$.

Despite the better understanding of typical and atypical clinical presentations of CADASIL gained overtime and the availability of genetic testing, misdiagnosis of CADASIL as MS is still not an infrequent scenario ${ }^{[13,14]}$. Even in typical cases, prolonged mistreatment of CADASIL with immunological treatments targeting MS has been described ${ }^{[14]}$. An older study revealed no association between $\mathrm{NOTCH} 3$ mutations and $\mathrm{MS}^{[15]}$. This led some authors to adapt the notion that the differential diagnostic question has a dichotomous answer, i.e. the patient has either CADASIL or $\mathrm{MS}^{[14]}$. This may not be always true. A rare but existing scenario implicates the presence of autoimmune (including MS-like) disorders, in patients with CADASIL. 
Table 1. Features useful in the differential diagnosis between CADASIL and MS

\begin{tabular}{|c|c|c|}
\hline & CADASIL & MS \\
\hline \multicolumn{3}{|l|}{ Clinical features } \\
\hline Autosomal dominant inheritence & Usually present & Usually absent \\
\hline Migraine with aura & $\begin{array}{l}\text { Increased frequency compared } \\
\text { to the general population }\end{array}$ & $\begin{array}{l}\text { Same frequency with the general } \\
\text { population }\end{array}$ \\
\hline Recurrent neurological symptoms & Ischemic & Demyelinative \\
\hline Vascular dementia & Yes & $\begin{array}{l}\text { Usually absent (cognitive and psychiatric } \\
\text { symptoms may exist) }\end{array}$ \\
\hline \multicolumn{3}{|l|}{ Neuroimaging findings } \\
\hline Characteristics of white matter lesions & $\begin{array}{l}\text { Initially focal, progressively con- } \\
\text { fluent, tend to spare the U fibers }\end{array}$ & $\begin{array}{l}\text { Oval lesions perpendicular to the lateral } \\
\text { ventricles } \\
\text { Gadolinium enhancing lesions }\end{array}$ \\
\hline Involvement of the temporal pole & Usually present & Usually absent \\
\hline Involvement of the external capsule & Usually present & Usually absent \\
\hline Involvement of corpus callosum & May be present & Usually present \\
\hline Involvement of deep subcortical nuclei (basal ganglia, thalamus) & Yes & No \\
\hline Spinal cord involvement & Extremely rare & Frequent \\
\hline Hemorrhagic lesions (usually microbleeds) & May be present & Absent \\
\hline \multicolumn{3}{|l|}{ CSF immunology } \\
\hline Oligoclonal bands (unmatched in serum) & Absent & Present \\
\hline $\lg$ index & Normal & Increased \\
\hline
\end{tabular}

CADASIL: cerebral autosomal dominant arteriopathy with subcortical infarcts and leucoencephalopathy; MS: multiple sclerosis; CSF: cerebrospinal fluid

\section{PATIENTS WITH CADASIL AND VARIOUS AUTOIMMUNE DISORDERS}

The possible involvement of autoimmune mechanisms in some patients with CADASIL has been hypothesized $^{[16]}$. The presence of antiphospholipid antibodies has been reported in two unrelated female patients with CADASIL, suggesting that the two conditions may co-occur ${ }^{[17]}$. Central nervous system angiitis may also co-occur with CADASIL ${ }^{[18]}$. The presence of antinuclear antibodies has been reported in at least 3 members of a CADASIL family, one of which was also positive for anti-SSA and anti-SSB antibodies ${ }^{[11]}$. Autoimmune thrombocytopenia has been observed in an elderly patient, leading to aspirin discontinuation and stroke recurrence ${ }^{[19]}$. Renal involvement with IgA mesangial deposition in addition to the typical granular osmiophilic material of CADASIL has been reported in patients from unrelated families with NOTCH3 mutations, leading to the diagnosis of CADASIL complicated with IgA nephropathy ${ }^{[20,21]}$.

The above observations indicate that autoimmune conditions may rarely coexist with CADASIL and the presence of one should not preclude the diagnosis of the other.

\section{POSSIBLE COMORBIDITY OF MS AND CADASIL}

Some patients with genetically proven CADASIL may present with MS or MS-like conditions. Oligoclonal bands in the cerebrospinal fluid (CSF), a characteristic finding in MS, are extremely uncommon in CADASIL, but they have been reported ${ }^{[22,23]}$. The occurrence of spinal cord lesions, especially longitudinal ones, are exceedingly rare in CADASIL and may be due to ischemia ${ }^{[24]}$ but, when present, they evoke a diagnostic challenge ${ }^{[25]}$. In one family with CADASIL, 3 members presented with cord lesions in the posterocentral area, cerebral lesions in locations compatible with both demyelination and typical CADASIL, positive antinuclear antibodies and CSF oligoclonal bands ${ }^{[26]}$. Another CADASIL patient with thoracic cord involvement, in the absence of CSF oligoclonal bands, showed paramagnetic enhancement of an internal capsule lesion and good response of his gait disorder to corticosteroids ${ }^{[27]}$. A ring enhancing lesion in the cerebellar peduncle and a solid enhancing lesion in the corona radiate were observed in a patient positive for CSF oligoclonal bands and with a high IgG index, who later developed new multiple enhancing lesions and new cervical spinal lesions ${ }^{[28]}$. 
Relapsing optic neuritis without CSF oligoclonal bands has been described in a CADASIL patient with sensorimotor leg deficit, showing good response to corticosteroids and later to glatiramer acetate ${ }^{[27]}$. According to the authors, this patient would otherwise fulfill the diagnostic criteria of MS.

Balo concentric sclerosis has been reported in a patient carrying a $\mathrm{NOTCH} 3$ mutation ${ }^{[29]}$. Oligoclonal bands were absent and response to corticosteroids was minimal. However, significant improvement was noted after 5 sessions of plasmapheresis. He was then treated as a clinically isolated syndrome with $\beta$-interferon-1a and no relapse was noted for at least 1 year.

The above reports of cases or families indicate that, rarely, MS or MS-like conditions may coexist with CADASIL. The presence of CSF oligoclonal bands or high IgG index and/or the responsiveness to immunological treatments points towards the autoimmune nature of these conditions. They may represent true MS or some other related demyelinative disease or an inflammatory form/component of CADASIL ${ }^{[27-29]}$. The cooccurrence of the two conditions could be coincidental. But, is there a possibility that $\mathrm{NOTCH} 3$ mutations may somehow provoke (or at least alter) autoimmune phenomena?

\section{THE INTERPLAY BETWEEN CADASIL AND AUTOIMMUNITY}

It has been hypothesized that an interaction may be normally present between the immune and NOTCH3 signaling systems. This interaction may be altered by $\mathrm{NOTCH} 3$ mutations or Notch3 dysfunction ${ }^{[30,31]}$. In addition, the gain of a novel/toxic function of the mutant Notch3 protein, suggested to occur in CADASIL ${ }^{[1,4]}$, may be associated, through altered protein-protein interactions, with immune dysregulation and/or presentation of new epitopes ${ }^{[27]}$ leading to autoimmunity. This presentation of new epitopes may be facilitated by abnormal aggregations of extracellular matrix proteins, forming complexes with the extracellular domain of the Notch3 receptor ${ }^{[32]}$. Dysregulation of T-cells by altered Notch3 function may offer an additional or alternative mechanism for inflammatory demyelination ${ }^{[31]}$.

Alterations of the vascular wall occurring in CADASIL ${ }^{[4]}$ are thought to affect the blood brain barrier and, indeed, many patients have CSF evidence of blood brain barrier dysfunction (increased protein) ${ }^{[23]}$. Such a dysfunction, possibly augmented by ischemia, may expose central nervous system antigens to the immune system, initiating an autoimmune reaction ${ }^{[28]}$. It seems possible however, that the NOTCH3 mutations alone are not enough to trigger autoimmunity since, most patients do not have such coexisting disorders. Other genetic or epigenetic factors may participate.

CADASIL is not the only genetic encephalopathy, which may (rarely) present with autoimmune comorbidity or be confused with MS. Indeed, some genetic white matter diseases, including adrenoleucodystrophy, may be complicated by an inflammatory component during disease progression ${ }^{[5]}$. Interestingly enough, some other genetic conditions may have both an ischemic and an inflammatory component, they may be accompanied by migraine with aura and ischemic events (including stroke or stroke-like episodes) and they may result in cognitive impairment and psychiatric/behavioral symptoms. Retinal vasculopathy with cerebral leucodystrophy (RVCL), due to mutations of TREX1 is one such disorder, presenting with many, sometimes overlapping phenotypes ${ }^{[33]}$. Renal and retinal involvement, together with contrast-enhancing mass lesions in brain imaging, distinguish this disorder from CADASIL. Mitochondrial diseases including MELAS ${ }^{[34]}$, $P O L G$-related ${ }^{[35]}$, and OPA1-related ${ }^{[36]}$ disorders may sometimes have an autoimmune component.

\section{CONCLUSION}

It is not infrequent for CADASIL to be mistaken for $\mathrm{MS}^{[37]}$. Better understanding of the disease is required for clinical neurologists and radiologists, in order to avoid diagnostic pitfalls and mistreatments. A much less frequent, yet existing scenario, is the co-occurrence of CADASIL and MS (or MS-like inflammatory 
condition). This co-occurrence may be incidental and the two disorders may progress in parallel, but unrelated to each other. Alternatively, the two disorders, once incidentally coexistent, may interact with each other, modulating the pathophysiological mechanisms and phenotypes. A third possibility is that CADASIL through various mechanisms may trigger autoimmune reactions, and either be complicated by an inflammatory component ("inflammatory form of CADASIL") or cause an MS-like disorder.

Mistreating CADASIL with immunomodulating treatments targeting MS should be avoided. However, the rare CADASIL patient with an inflammatory component should not be denied the use of immunological treatments.

\section{DECLARATIONS}

\section{Authors' contributions}

Concept and definition of intellectual content: Paraskevas GP, Kapaki E

Literature search: Paraskevas GP, Constantinides VC

Manuscript preparation: Paraskevas GP, Constantinides VC

Manuscript editing and manuscript review: Kapaki E

\section{Availability of data and materials}

Not applicable.

\section{Financial support and sponsorship}

None.

\section{Conflicts of interest}

All authors declare no conflicts of interest.

\section{Ethics approval and patient consent}

This review is part of the study named "Migraine and Specific Vasculopathies Registry" of the 1st Department of Neurology, National and Kapodistrian University of Athens, which has been approved by the Scientific and Ethics Committee of Eginition Hospital and is not supported by any funding. The patients whose MRIs are shown in Figure 1, gave informed consent for inclusion in the study and publication of their MRI images.

\section{Consent for publication}

Not applicable.

\section{Copyright}

(c) The Author(s) 2018.

\section{REFERENCES}

1. Chabriat H, Joutel A, Dichgans M, Tournier-Lasserve E, Bousser MG. CADASIL Lancet Neurol 2009;8:643-53.

2. Federico A, Di Donato I, Bianchi S, Di Palma C, Taglia I, et al. Hereditary cerebral small vessel diseases: a review. J Neurol Sci 2012;322:25-30.

3. Singhal S, Rich P, Markus HS. The spatial distribution of MR imaging abnormalities in cerebral autosomal dominant arteriopathy with subcortical infarcts and leukoencephalopathy and their relationship to age and clinical features. Am J Neuroradiol 2005;26:2481-7.

4. Tikka S, Baumann M, Siitonen M, Pasanen P, Pöyhönen M, et al. CADASIL and CARASIL. Brain Pathol 2014;24:525-44.

5. Kalman B, Leist TP. Familial multiple sclerosis and other inherited disorders of the white matter. Neurologist 2004;10:201-15.

6. O'Riordan S, Nor AM, Hutchinson M. CADASIL imitating multiple sclerosis: the importance of MRI markers. Mult Scler 2002;8:430-2.

7. Coto E, Menéndez M, Navarro R, García-Castro M, Alvarez V. A new de novo Notch3 mutation causing CADASIL. Eur J Neurol 2006;13:628-31.

8. Pescini F, Nannucci S, Bertaccini B, Salvadori E, Bianchi S, et al. The Cerebral Autosomal-Dominant Arteriopathy With Subcorti- 
cal Infarcts and Leukoencephalopathy (CADASIL) Scale: a screening tool to select patients for NOTCH3 gene analysis. Stroke 2012;43:2871-6.

9. He D, Chen D, Li X, Hu Z, Yu Z, et al. The comparisons of phenotype and genotype between CADASIL and CADASIL-like patients and population-specific evaluation of CADASIL scale in China. J Headache Pain 2016;17:55.

10. Pandey T, Abubacker S. Cerebral autosomal dominant arteriopathy with subcortical infarcts and leukoencephalopathy: an imaging mimic of multiple sclerosis. A report of two cases. Med Princ Pract 2006;15:391-5.

11. Paraskevas GP, Bougea A, Synetou M, Vassilopoulou S, Anagnostou E, et al. CADASIL and autoimmunity: coexistence in a family with the R169C mutation at exon 4 of the NOTCH3 gene. Cerebrovasc Dis 2014;38:302-7.

12. Paraskevas GP, Constantinides VC, Bougea A, Gerakoulis E, Yapijakis C, et al. Cerebral autosomal dominant arteriopathy with subcortical infarcts and leukoencephalopathy presenting with postpartum psychosis and late-onset stroke. Future Neurol 2016;1:207-13.

13. Joshi S, Yau W, Kermode A. CADASIL mimicking multiple sclerosis: The importance of clinical and MRI red flags. J Clin Neurosci 2017;35:75-7.

14. Carone DA. CADASIL and multiple sclerosis: A case report of prolonged misdiagnosis. Appl Neuropsychol Adult 2017;24:294-7.

15. Broadley SA, Sawcer SJ, Chataway SJ, Coraddu F, Coles A, et al. No association between multiple sclerosis and the Notch3 gene responsible for cerebral autosomal dominant arteriopathy with subcortical infarcts and leukoencephalopathy (CADASIL). J Neurol Neurosurg Psychiatry 2001;71:97-9.

16. Del Río Espínola A, Solé E, Montaner J. Pathophysiology of CADASIL disease. Med Clin (Barc) 2010;135:222-30.

17. Pantoni L, Sarti C, Pescini F, Bianchi S, Bartilini L, et al. Thrombophilic risk factors and unusual clinical features in three Italian CADASIL patients. Eur J Neurol 2004;11:782-7.

18. Schmidley JW, Beadle BA, Trigg L. Co-occurrence of CADASIL and isolated CNS angiitis. Cerebrovasc Dis 2005;19:352-4.

19. Nannucci S, Pescini F, Valenti R, Ciolli L, Bianchi S, et al. Stroke recurrence in an elderly CADASIL patient on aspirin discontinuation due to severe auto-immune thrombocytopenia. Aging Clin Exp Res 2010;22:98-9.

20. Kusaba T, Hatta T, Kimura T, Sonomura K, Tanda S, et al. Renal involvement in cerebral autosomal dominant arteriopathy with subcortical infarcts and leucoencephalopathy (CADASIL). Clin Nephrol 2007;67:182-7.

21. Ragno M, Trojano L, Pianese L, Boni MV, Silvestri S, et al. Renal involvement in cerebral autosomal dominant arteriopathy with subcortical infarcts and leukoencephalopathy (CADASIL): report of a case with a six-year follow-up. Histol Histopathol 2012;27:1307-14.

22. Chabriat H, Vahedi K, Bousser MG, Iba-Zizen MT, Joutel A, et al. Clinical spectrum of CADASIL: a study of 7 families. Cerebral autosomal dominant arteriopathy with subcortical infarcts and leukoencephalopathy. Lancet 1995;346:934-9.

23. Dichgans M, Wick M, Gasser T. Cerebrospinal fluid findings in CADASIL. Neurology 1999;53:233.

24. Hinze S, Goonasekera M, Nannucci S, Quaghebeur G, Briley D, et al. Longitudinally extensive spinal cord infarction in CADASIL. Pract Neurol 2015;15:60-2.

25. Pinto WB, Souza PV, Oliveira AS. Longitudinally extensive transverse myelopathy in a patient with CADASIL. Arq Neuropsiquiatr 2015;73:812.

26. Bentley P, Wang T, Malik O, Nicholas R, Ban M, et al. CADASIL with cord involvement associated with a novel and atypical NOTCH3 mutation. J Neurol Neurosurg Psychiatry 2011;82:855-60.

27. Collongues N, Derache N, Blanc F, Labauge P, de Seze J, et al. Inflammatory-like presentation of CADASIL: a diagnostic challenge. BMC Neurol 2012;12:78.

28. Schiess N, Huether K, Szolics M, Agarwal G, El-Hattab AW, et al. Multiple sclerosis or “inflammatory CADASIL?”: Case Report and review of the literature. Clin Neurol Neurosurg 2018; doi: 10.1016/j.clineuro.2018.01.035

29. Chitnis T, Hollmann TJ. CADASIL mutation and Balo concentric sclerosis: a link between demyelination and ischemia? Neurology 2012;78:221-3.

30. Rampal R, Luther KB, Haltiwanger RS. Notch signaling in normal and disease States: possible therapies related to glycosylation. Curr Mol Med 2007;7:427-45.

31. Jurynczyk M, Jurewicz A, Raine CS, Selmaj K. Notch3 inhibition in myelin-reactive T cells down-regulates protein kinase C theta and attenuates experimental autoimmune encephalomyelitis. J Immunol 2008;180:2634-40.

32. Monet-Leprêtre M, Haddad I, Baron-Menguy C, Fouillot-Panchal M, Riani M, et al. Abnormal recruitment of extracellular matrix proteins by excess Notch3ECD: a new pathomechanism in CADASIL. Brain 2013;136:1830-45.

33. Kavanagh D, Spitzer D, Kothari PH, Shaikh A, Liszewski MK, et al. New roles for the major human 3'-5' exonuclease TREX1 in human disease. Cell Cycle 2008;7:1718-25.

34. Finsterer J, Zarrouk-Mahjoub S. Autoimmunity in MELAS. Ann Clin Lab Sci 2018;48:255-6.

35. Harris MO, Walsh LE, Hattab EM, Golomb MR. Is it ADEM, POLG, or both? Arch Neurol 2010;67:493-6.

36. Yu-Wai-Man P, Griffiths PG, Gorman GS, Lourenco CM, Wright AF, et al. Multi-system neurological disease is common in patients with OPA1 mutations. Brain 2010;133:771-86.

37. Koutroulou I, Karapanayiotides T, Grigoriadis N, Karacostas D. CADASIL presenting with spontaneous intracerebral hemorrhage: report of a case and description of the first family in Northern Greece. Hippokratia 2016;20:76-9. 